\title{
Ownership and Control: A Small-World Analysis
}

\author{
Martin J. Conyon ${ }^{1^{*}} \&$ Mark R. Muldoon ${ }^{2}$ \\ ${ }^{1}$ ESSEC Business School \\ \& The Wharton School \\ ${ }^{2}$ School of Mathematics, University of Manchester
}

December, 2007

\begin{abstract}
In this paper we investigate the ownership and control of British firms using recent techniques from computational graph theory. Specifically, we analyze the 'small-world' of ownership and control. A small-world is a network whose actors are linked by a short chain of acquaintances (short path-lengths), but at the same time have a strongly overlapping circle of friends (high clustering). We simulate a set of corporate worlds using an ensemble of random-graphs introduced by Chung and $\mathrm{Lu}(2002 a, b)$. We find that the corporate governance network structures analyzed here are more clustered ('clubby') than would be predicted by the random-graph model. Path-lengths, though, are generally not shorter than expected. In addition, we investigate the role of financial institutions: potentially important conduits creating connectivity in corporate networks. We find such institutions give rise to systematically different network topologies.
\end{abstract}

\footnotetext{
*Acknowledgements We would like to thank Joel Baum, Ron Burt, Jerry Davis, Pat Doreian, Bruce Kogut and Tim Rowley for usful comments and discussions during the preparation of this manuscript. We are especially grateful to the organizers and participants at the Network Strategies conference at the Rotman School, Toronto in 2007 who helped shape the ideas in this paper. In addition, we appreciate comments from seminar participants at the University of Manchester, Singapore Management University, the Wharton School as well as attendees of the Small-World conferences at IESE, Spain (2005) and ALMA Graduate School, University of Bologna (2006). Financial support from the Wharton Center for Leadership and Change Management is gratefully acknowledged.
} 


\section{Introduction}

Social network analysis is a critical methodology for analyzing the inter-relationships between actors (e.g. Burt (1992), Wasserman and Faust (1994)). Recent advances in computational graph theory have opened up exciting new techniques for investigating complex network structures in diverse disciplines such as sociology, economics, physics, the life-sciences and organizational studies (Newman (2003), Jackson (2005)). In this paper we use techniques introduced by Newman et al. (2001) and more recently Chung and Lu (2002a,b); Chung et al. (2003) to provide a social network analysis of the ownership and control of publicly traded UK firms. This paper extends our previous network evaluation of corporate boards (Conyon and Muldoon (2006)).

We contribute to the extant social network, strategy and corporate governance literature in two distinct ways. First, we argue that contemporary developments in graph theory are capable of providing deep insights into the structure of social networks in organizational settings. We illustrate this by presenting a social network analysis of the governance of publicly traded firms (i.e. the ownership and control of firms). Specifically, we discuss important concepts such as 'bipartite graphs' , 'small-world' models, and 'random-graphs' and show how they can be profitably applied to the analysis of corporate governance phenomenon. ${ }^{1}$ Second, we present empirical evidence on actual ownership and control (board) networks. Using data on a large set of publicly traded UK firms in year 2000, we test whether observed ownership and control networks can be characterized as a 'small-world'. Our research builds upon prior small-world studies in organizational and business settings. Specifically, we use the methods of Newman et al. (2001) and the family of random graphs recently introduced by Chung and Lu (2002b,a); Chung et al. (2003).

Our research context is the governance of publicly traded firms, sometimes referred to as 'AngloSaxon' enterprises. There are two distinctive features of such firms in the United States and the United Kingdom. First, ownership is diffuse such that many different shareholders each own only a small fraction of the firm's equity and second, de facto control of the firm resides with the CEO and the board of directors. ${ }^{2}$ The social network approach offered here contrasts with the canonical

\footnotetext{
${ }^{1}$ Each of these ideas is explained fully in Section 3. For example, one can informally think of a bipartite graph as a social network consisting of two distinct types of actors. Here we discuss two kinds of bipartite graph: an 'ownership' network, which consists of firms and their shareholders, and a 'control' network, which consists of boards and their directors.

${ }^{2}$ See Franks et al. (2005) for an analysis of the evolution of ownership in the United Kingdom. Useem (1984) provides a sociological account of the inner circle of boards and directors.
} 
agency model which focuses on the ownership and control of a single firm without reference to its connections to other organizations. The separation of ownership from control gives rise to an agency problem: the CEO can potentially engage in opportunistic self-serving activities. Tirole (2005) gives an excellent account of the corporate finance approach to the classic principal-agent problem. The history of Anglo-Saxon corporate governance since Berle and Means (1932) has centered on how to resolve this agency problem. In consequence, the design of compensation contracts, monitoring by independent directors or the discipline imposed by an active takeover market have been widely studied. However, this representation of the firm is incomplete. Firms are not independent islands in a sea of economic activity. Instead, firms are intrinsically connected to each other: a given firm typically shares a common owner or board member with at least one other firm. These ties are sufficient to connect firms together in a giant network. Such connectivity, we argue, has significant implications. The presence of short path-lengths and high clustering promotes the rapid diffusion of knowledge, information, ideas and even business practices throughout the corporate network (see Cowan and Jonard, 2004).

Our paper is motivated, in part, by a famous study by Stanley Milgram who suggested that the social world of the USA is 'small' in the sense that most pairs of Americans are connected by a rather short chain of acquaintance (around six intermediates) — see Milgram (1967). This is true even though (a) most Americans are acquainted with only a tiny fraction of the country's population and (b) circles of acquaintance tend to be strongly overlapping - that is, one's friends have a tendency to be friends in their own right. In the last decade or so scholars from diverse disciplines, including physics, sociology and economics, have become very interested in this phenomenon and have sought to understand how it arises. An important strand of this work is the exploration of various ensembles of random graphs (see Newman et al., 2001; Chung and Lu, 2002a,b; Chung et al., 2003). In our study we are interested in the application of these principles to the social network of British ownership and control.

A small-world, then, is a network whose actors are linked by a short chain of acquaintances, but at the same time have a strongly overlapping circle of friends. These two distinctive properties, the coexistence of short path lengths and a high degree of local clustering, constitute the small-world phenomenon. This immediately prompts the question 'small compared to what'? In response, there has been considerable effort in the graph theory literature to develop a sensible and tractable answer to this question. Broadly speaking, the answer is to compare the observed data to some suitably 
assembled ensemble (collection) of random graphs. Early work made comparisons with so-called Poisson random graphs introduced by Erdős and Rényi (1959). Indeed, important contributions to the small-world of corporate governance literature by Kogut and Walker (2001) and Davis, Yoo and Baker (2003) did precisely this. However, it is now known that social networks have particular structural properties (for example, directors automatically know each other by virtue of sitting on the same board) that makes the comparison to the Poisson graph inappropriate. Consequently, more recent efforts have used graph ensembles designed to capture more features of the social network.

In an important paper Newman, Strogatz and Watts (2001) examined affiliation networks which recognize that the network of corporate governance has a bipartite structure. That is, the network has two distinct kinds of actors, for example, boards and the directors who sit on them. One of the consequences of this structure is that one should automatically expect a high degree of clustering among directors; after all, as noted above, the directors who sit on a given board know each other. The main accomplishment of Newman et al. (2001) is to provide numerical predictions of the smallworld statistics that one can derive from an appropriately assembled random corporate universe. It is these expected values of the path length and clustering coefficient that form a legitimate benchmark to compare actual data against.

However, their methods yield only mean estimates of the small-world statistics and provide little guidance as to other properties of the distribution, such as the variance of clustering and path lengths. Our contribution in this paper is to consider a slightly different collection of random graphs introduced by Fan Chung and Linyuan Lu (see Chung and Lu, 2002a,b; Chung et al., 2003). This family of random graphs have two attractive properties: first, they are more tractable analytically and second lend themselves readily to numerical simulation. This latter property means that the researcher is able to simulate as many hundreds of corporate universes as desired and so examine the entire distribution of the small-world statistics. In our paper, we do precisely this. The research question we ask has the flavor of a hypothesis test: is the real corporate universe similar to, or different from, a randomly assembled business world? Newman et al. (2001, 2002) suggested that the corporate elite was rather close, in a certain distributional sense, to a random one. If this really is the case, then the world is actually no smaller than one would expect by chance. We extend this research by focusing on the family of random graphs introduced by Chung and Lu $(2002 a, b)$; Chung et al. (2003). 
The rest of the paper is organized as follows. In Section 2 we show that the ownership and control of firms can be characterized as a bipartite graph. We provide concrete examples to show this. In Section 3 we describe germane aspects of small-world theory. Our focus is on the class of models introduced by Chung and Lu (2002a,b); Chung et al. (2003) and how they may be applied to the corporate governance social network. In Section 4 we describe the British data to be used in this study. We present the results and deduce that the world is, indeed, 'small', but only in the sense that the corporate world appears more clustered than expected. Path-lengths, however, are no smaller than expected, even though they form a very small fraction of the available vertices in the network. The innovation here is that we provide an appropriate benchmark, based on Chung-Lu random graphs, to evaluate the significance of smallness. In addition, we analyze the importance of financial institutions in the network. It is often argued that banks are important conduits creating connectivity in corporate networks. We demonstrate that the presence of financial institutions does indeed give rise to different network topologies. Finally in Section 5 we offer some concluding remarks.

\section{Social networks of ownership and control}

\subsection{Motivation}

Our concern in this paper is to analyze the ownership and control of the Anglo-Saxon enterprise using the tools of contemporary social network analysis. We focus on the type of firm that is publicly-traded on stock exchanges in economies like the United States and the United Kingdom. Such firms, as is well-known, are characterized by diffuse ownership in the sense that a myriad different shareholders each own only a small fraction of the firm's equity. In addition, the firm is controlled by a Chief Executive Officer (CEO) and the board of directors. Importantly, the firm's owner (shareholder) does not make strategic decisions about the firm' assets. Instead, the task of running the firm is delegated to a separate body (the CEO and board of directors) giving rise to a de facto separation between ownership and control.

The theoretical lens typically used by economists to analyze such situations is the principalagent model. In this context the principal would be the shareholder and the agent would be the CEO. ${ }^{3}$ The divorce between ownership and control implies that the principal (shareholder) cedes

\footnotetext{
${ }^{3}$ The principal-agent paradigm covers any hierarchical task-delegated relationship. For example, the relation
} 
the task of running the firm to an agent (the CEO). The mere fact of this delegation suggests that the agent may have access to private information that is not similarly available to the principal. For example, the shareholder may not know with certainty the true skills and quality of the CEO when he or she is initially appointed. Alternatively, the shareholder may not be able to perfectly know whether the CEO is taking the right actions to safeguard the owner's asset. For example, the CEO may be taking unwarranted perks in the form of excessive pay or empire-building. Each of these problems arises because of the private knowledge of the agent. ${ }^{4}$ A primary concern of the principal-agent literature has been how to design an optimal contract in order to resolve the tensions between the principal and agent arising from such natural asymmetries of information. There is a vast literature on this. For example, a central research theme in agency theory centers on how to design an optimal compensation contract to align the interests of CEOs with owners. Such models typically predict the use of stock options, bonus payments or profit sharing as a potential solution. Alternative mechanisms to alleviate the costs associated with the separation of ownership and control include monitoring activities. The firm might appoint auditors, establish audit committees and hold regular audits to establish the veracity of corporate accounts for example.

Whilst the agency perspective provides important insights into the relationships between actors in an economy it is not the only way to model such interactions. Our conjecture in this paper is that the principal-agent representation of the nexus of ownership and control relationships is incomplete. It is incomplete in the sense that the models are generally applied to information asymmetries arising in a single context. For example, how to solve the shirking (moral hazard) problem between a manager-worker in a single firm. Or how a shareholder can motivate the CEO in a single firm. The focus of attention is not, in general, on the connections that might arise between the whole network of firms. In short, most of the important features the agency model can be articulated in a single hierarchical relation between a single principal and a single agent. ${ }^{5}$ Interconnections between firms are ignored. However, firms are not independent islands in a sea of economic activity. Instead, they are connected to each other in important ways. For example,

between manager and worker, landlord and tenant, client firm and its advisor, and insurance company and a cardriver or a home-owner and a building contractor etc.

${ }^{4}$ The literature has distinguished between moral hazard and adverse selection problems. For instance, a moralhazard occurs if the actions taken by the agent are hidden from the principal (e.g. the owner cannot observe perfectly the CEOs effort or his diligence in selecting projects). Adverse-selection occurs when the agent's true type is hidden from the principal (e.g. the owner does not know the true skills embodied in the CEO).

${ }^{5}$ Extensions to the model are possible, for example to a principal multi-agent framework. But even here the focus remains on the design of the optimal contract rather than the importance of connections in the network structure. 
Figure 1: The Network Structure of Ownership and Control: The top half is a bipartite graph. Vertices labeled A to K can represent either company directors or the firm's shareholders. Vertices 1 to 4 represent either the board of directors or the firm. The bottom half shows the projections: the board/firm projection is to the left and the director/ownership projection is to the right.
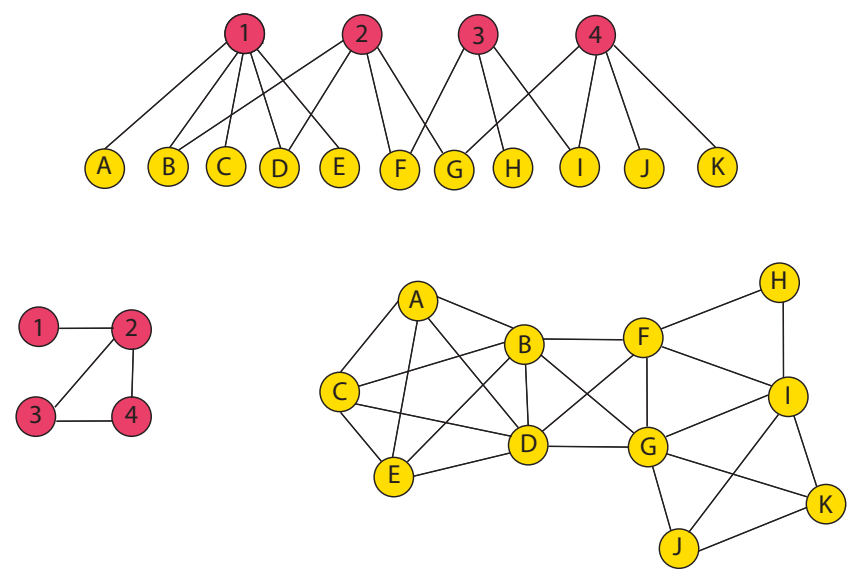

a given firm typically shares a common owner with at least one other firm. In addition, the same firm might share a common board member with another firm. Or indeed, it might share a common advisor such as a compensation consultant or audit company with another firm. These ties are sufficient to connect firms together in a giant complex network. Such connectivity, we conjecture, will have significant implications for firm strategy. For example, the presence of short path-lengths in the network and/or a high degree of clustering may promote the rapid diffusion of knowledge, information, ideas and even business practices throughout the corporate network (see Cowan and Jonard, 2004).

\subsection{Corporate governance relations as bipartite graphs}

An important feature of our paper is the representation of the interconnections between actors in the corporate governance system as bipartite graphs. To understand this we first need to introduce some necessary terminology. A graph or network is a set of items termed vertices (sometimes also called nodes) and edges. The vertex is the fundamental unit of a network and an edge is a link connecting two vertices. Two vertices are adjacent if connected by an edge. The number of edges connected to (or incident on) a vertex is called the degree and is a local measure of the vertex's centrality in the graph. A vertex's connected component is that part of the graph consisting of the 
vertex itself and all those others that can be reached by paths running along the edges. A geodesic is a shortest path ${ }^{6}$ (in the sense of traversing the fewest edges) that connects two vertices and finally, the distance between two vertices is the number of edges in a geodesic connecting them.

We are now in a position to represent many corporate governance relationships as a bipartite graph. To be concrete, a bipartite graph is one whose vertices can be divided into two distinct sets and whose edges connect only unlike kinds of vertices. Consider how one might represent the owners of a firm and the firm itself as a such a bipartite graph. There are two sets of vertices: the first set are the firms themselves and the second set are the owners of the firm. Figure 1 illustrates such a bipartite graph and its projections. In the upper-half of the figure the two sets of vertices are displayed horizontally. Vertices $\{1,2,3,4\}$ represents firms and vertices $\{A, B, \ldots, J, K\}$ represent shareholders. An edge exists between $X$ and $Y$ if a shareholder owns at least on share in a given publicly traded firm. Notice that the edges run between the two sets of vertices. The bipartite graphs gives rise to two distinct projections. These two separate graphs are drawn in the lower half of Figure 1 and are 'projections' of the bipartite graph onto one of its two sets of vertices. One might call these the 'ownership projection' and the 'firm projection'. In Section 3 we calculate small-world statistics for each of these projections. ${ }^{7}$ This procedure for understanding the relation between different sets of actors in a social network is quite general. The set of vertices $X=\{1,2,3,4\}$ can represent a firm and vertices $Y=\{A, B, \ldots, J, K\}$ represent directors. In this case an edge exists between the two vertices of a director is the member of the board.

To illustrate the bipartite representation of ownership and control consider the two companies in Table 1: Marks and Spencer Plc. (a high-street retailer) and Standard Chartered Plc. (a bank). ${ }^{8}$ Suppose we are interested in the firms' boards and directors. The two firms can be represented like the vertices in the upper-half of Figure 1 and the directors like the vertices in the lower-half. Marks and Spencer Plc. and Standard Chartered Plc. are linked since they share a common director: Sir Ralph Robins, who is a non-executive (outside) director at each firm. Table 1, though, is only a partial representation of the links between firms generated by shared board members. The final column is a dummy variable indicating whether the board member has at least one additional director appointment. Marks and Spencer Plc. is connected to Standard Chartered Plc. via Sir Ralph Robins, but is also connected to other listed firms (not shown) since Dame Stella Rimington,

\footnotetext{
${ }^{6}$ A pair of vertices may be connected by several paths that share the shortest length.

${ }^{7}$ Specifically, path lengths $(L)$ and clustering coefficients $\left(C_{\triangle}\right)$ for each projection separately.

${ }^{8}$ The data refer to year 2000.
} 
J K Lomax, and I P Sedgwick also hold additional directorships at other firms. ${ }^{9}$

In a similar fashion we could examine the ownership structure of the two firms. This is illustrated in Table 2. Under UK corporate law, ownership stakes exceeding 3\% are reported and can be observed by the researcher. We therefore list all owners (who are not board members) with share stakes exceeding this critical threshold. Table 2 illustrates that Marks and Spencer has two such owners, while Standard Chartered has four. In the case of Marks and Spencer the two largest shareholders own about $10.2 \%$ of the company and the four largest shareholders in Standard Chartered own about 25\%. There is not a single controlling block holder in either case - this is consistent with the Anglo-Saxon model that ownership is diffuse with each shareholder typically owning a small fraction of the firm's common equity. ${ }^{10}$ The two example firms are not linked by a common shareholder. However, the final column is the number of listed companies in which the named shareholder has a share stake exceeding 3\%. For example, the Prudential Corporation owns about $4.7 \%$ of Standard Chartered. In addition, it owns at least $3 \%$ share stakes in 136 other publicly listed UK firms. In Section 4 we document the general pattern of ownership.

\section{The small-world model}

The small-world theory analyzed in this paper is described in Newman et al. (2001) and Jackson (2005). We can now describe two main properties that characterize a "small world", namely the notions of mean path length and clustering.

The first property of the small-world model is short mean path-lengths. That is, randomlychosen pairs of vertices turn out to be unexpectedly close to each other. A graph with $N$ vertices contains $N(N-1) / 2$ unordered pairs of vertices. If these are numbered $1,2, \ldots, N$ and $d_{i, j}$ is the distance between vertex $i$ and $j$ then one can calculate the typical (average) distance as:

$$
L=\frac{2}{N(N-1)} \sum_{i<j} d_{i, j}
$$

In our numerical work we compute $L$ from a complete list of the $d_{i, j}$, found using Johnson's All-

\footnotetext{
${ }^{9}$ Of the 29 board members listed in Table 1, 10 hold director appointments at other publicly listed firms.

${ }^{10}$ The case of Standard Chartered is slightly anomalous in this respect. Tan Sri Khoo Teck Puat was Singapore's wealthiest man, until his death in 2004. His fortune was derived from share ownership in British bank Standard Chartered, which he bought up in the 1980s.
} 
Table 1: The Board of Directors

\begin{tabular}{lllc}
\hline Company name & Name & Role & 'Interlock' \\
\hline Marks and Spencer Plc. & L Vandevelde & Exec & \\
Marks and Spencer Plc. & R W C Colvill & Exec & Yes \\
Marks and Spencer Plc. & A McWalter & Exec & \\
Marks and Spencer Plc. & D Norgrove & Non-Exec & \\
Marks and Spencer Plc. & A Ball & Non-Exec & Yes \\
Marks and Spencer Plc. & Sir Michael Perry CBE & Non-Exec & \\
Marks and Spencer Plc. & Dame Stella Rimington DCB & Non-Exec & \\
Marks and Spencer Plc. & Sir David Sieff & Non-Exec & \\
Marks and Spencer Plc. & B F Baldock CBE & Non-Exec & Yes \\
Marks and Spencer Plc. & Sir Ralph Robins & Non-Exec & Yes \\
Marks and Spencer Plc. & J K Lomax & Exec & \\
Standard Chartered Plc. & Sir Patrick Gillam & Exec & \\
Standard Chartered Plc. & G S Talwar & Exec & \\
Standard Chartered Plc. & P N Kenny & Non-Exec & Yes \\
Standard Chartered Plc. & The Rt Hon Lord Stewartby RD & Exec & \\
Standard Chartered Plc. & C N A Castleman & Exec & \\
Standard Chartered Plc. & E M Davies & Exec & \\
Standard Chartered Plc. & K S Nargolwala & Exec & \\
Standard Chartered Plc. & C A Keljik & Exec & \\
Standard Chartered Plc. & M DeNoma & Non-Exec & \\
Standard Chartered Plc. & D G Moir & Non-Exec & Yes \\
Standard Chartered Plc. & A W P Stenham & Non-Exec & \\
Standard Chartered Plc. & R C Chan & Non-Exec & Yes \\
Standard Chartered Plc. & H E Norton & Non-Exec & \\
Standard Chartered Plc. & K A V Mackrell & Non-Exec & \\
Standard Chartered Plc. & H KwonPing & Non-Exec & Yes \\
Standard Chartered Plc. & Sir C Chow & Non-Exec & Yes \\
Standard Chartered Plc. & Sir Ralph Robins & Non-Exec & Yes \\
Standard Chartered Plc. & B Clare & & \\
\hline
\end{tabular}

Table 2: The Ownership of Firms

\begin{tabular}{lllc}
\hline Company name & Shareholder & Ownership & Clients \\
\hline Marks and Spencer Plc. & Franklin Resources Inc & 5.89 & 40 \\
Marks and Spencer Plc. & Brandes Investment Partners & 4.319 & 17 \\
Standard Chartered Plc. & CGNU Plc. & 3.026 & 184 \\
Standard Chartered Plc. & Prudential Corporation Plc. & 4.725 & 137 \\
Standard Chartered Plc. & Tan Sri Khoo Teck Puat & 13.994 & 1 \\
Standard Chartered Plc. & Scottish Widows & 3.003 & 71 \\
\hline
\end{tabular}


Pairs-Shortest-Path algorithm. In the context of boards, the term $L$ measures the number of steps in a chain of shared directors that it takes to get from a source board to a target board.

The second property of the small-world model is high 'clustering'. This is the propensity for one's network neighbors to be neighbors in their own right. It is a measure of network density. Following Newman et al. (2001) we calculate the following clustering coefficient for the graph as a whole:

$$
C_{\triangle}=\frac{3 \times(\text { number of triangles in the graph })}{(\text { number of connected triples })}
$$

where a triangle is a set of three distinct vertices $j, k, l$ in which each vertex is connected to both the other two. A connected triple is a set of three vertices $j, k, l$ in which $j$ is connected to $k$ and $k$ is connected to $l$ (though $l$ need not be connected to $j$ ). $C_{\triangle}$ is also called the transitive closure of the graph and $0<C_{\triangle}<1$. In our data, a large value of $C_{\triangle}$ is a measure of how 'clubby' boards of directors are. When $C_{\triangle}=1$ everybody is connected to everyone else.

\subsection{Random graphs I: Newman, Strogatz and Watts}

We have identified the properties of a small-world. Next, one needs to agree on what is meant by $L$ being 'small' and $C_{\triangle}$ being 'large' in order to deduce the presence of a small-world. A now standard approach is to compare $L$ and $C_{\triangle}$ from real social networks to the numbers one would expect to measure in randomly-assembled graphs that share some properties with the observed network.

In their seminal work on random graphs, Erdős and Rényi imagined fixing the number of nodes $N$ and then deciding, at random, independently and with fixed probability $p$, whether each of the graph's $N(N-1) / 2$ possible edges exist (see Erdős and Rényi $(1959,1960)$ ). In such a graph each vertex can have as many $(N-1)$ edges - one connecting it to each of the remaining nodes - and in expectation a fraction $p$ of these will exist, so such a graph has mean degree $z=p(N-1)$. More generally, the degree distribution is binomial:

$$
p_{k}=\left(\begin{array}{c}
N-1 \\
k
\end{array}\right) p^{k}(1-p)^{N-k-1}
$$

for $k \in\{0,1, \ldots, N-1\}$ and zero otherwise. Here $p_{k}$ is the probability of finding a node of degree $k$. Erdős and Rényi were primarily interested in how the qualitative properties of such graphs changed 
as they held the mean degree $z$ constant, but allowed the number of nodes to tend to infinity. In the limit the degrees of the nodes have a Poisson distribution $p_{k}=z^{k} e^{-z} / k$ !. As a shorthand we will refer to graphs with Poisson degree distributions as Poisson random graphs. Such graphs have studied extensively (see for example Bollobás, 2001) and have been used as the benchmark by which to compare social networks. For example, see Newman et al. (2001) as well as Davis et al. (2003), both of whom compare small-world statistics from actual social networks to those expected for random graphs with a Poisson degree distribution.

More recently, an alternative and more appropriate benchmark was proposed by Newman et al. (2001, 2002). Newman, Strogatz and Watts (NSW) developed a way to calculate the expected values of both $L$ and $C_{\triangle}$ using the machinery of probability generating functions ${ }^{11}$. Their approach takes as its input the two empirical degree sequences - the distribution of board size (number of seats on the board) and the distribution of workload among directors (the vast majority of whom sit on only a single board, though a few serve on many more) - and combines them to predict degree sequences for the board and director projections. Their predictions are large-graph limits for a certain family of randomly-assembled social networks, but they are in surprisingly good agreement with empirical data, especially for the distribution of degree in the director projection.

Using the machinery of generating functions one can calculate the expected mean degree, path length and clustering coefficient for the graph. The degree distribution associates a probability $p_{k}$ with each possible value of the degree $k$, where $k$ is any non-negative integer. Such distributions permit one to construct a probability generating function, $G(x)$, which is a function of one variable defined by the infinite sum: $G(x)=\sum_{k=0}^{\infty} p_{k} x^{k}$ and it is a general property of generating functions that $G(1)=1$. For generating functions arising from degree distributions the mean degree is given by: $z=\langle k\rangle=\sum_{k=0}^{\infty} k p_{k}=G^{\prime}(1)$ Here the angle brackets are the expectation operator. ${ }^{12}$

A bipartite graph of either the control network (board-to-director) or the ownership network (shareholder-to-firm) has two empirical degree distributions. This gives rise to two separate generating functions. Consider the case of the control network. We denote $f_{0}(x)$ as the function that generates the degree distribution for the directors (i.e. the distribution of the number of boards on which a director sits). For concreteness, say that the frequency with which one finds a director

\footnotetext{
${ }^{11}$ See Wilf (1990) for a discussion of generating functions.

${ }^{12}$ Formulae for higher moments of the distribution, as well for the generating functions for sums of independent samples from distribution are also simply related to $G(x)$. Generating functions arising from empirical degree distributions are finite polynomials.
} 
serving on $j$ boards is $p_{j}$. Then $f_{0}(x)$ is given by $f_{0}(x)=\sum_{j} p_{j} x^{j}$. The second degree distribution for boards (i.e. the distribution of the number of directors per firm) is given as $g_{0}(x)$. If the empirical frequency for boards made up of $k$ directors is $q_{k}$ then $g_{0}(x)=\sum_{k} q_{k} x^{k}$.

Our real objects of interest are the two projections of the bipartite graph: one whose nodes are boards and whose edges represent shared directors (the graph showing board interlocks) and another whose nodes are directors and whose edges connect directors that sit on one (or more) board in common. The charm of the generating function approach is that it permits one to start with the empirical generating functions $f_{0}(x)$ and $g_{0}(x)$ and derive expressions for the generating functions for the degree distributions in the projections. We will refer to these derived distributions as the theoretical degree distributions to emphasize that they are not measured directly from the data. Instead, they describe the distribution of degrees one would find in random corporate worlds constructed by applying the methods of the previous section to the empirical degree distributions. These theoretical degree distributions are the device by which we obtain expected values of the small-world statistics without having to generate and analyze random graphs.

Suppose now that we are investigating a corporate world in which $N$ directors sit on $M$ boards. Suppose further that the mean number of seats on a board is $\nu$ and that the mean number of directorships held is $\mu$. The bipartite graph representing this community has one edge for each seat on a board and so

$$
\nu M=(\text { number of seats on boards })=\mu N .
$$

Define the generating function for theoretical degree distribution of the projection onto directors as $G_{0}(x)$. We denote the expected degree as $\langle z\rangle$, the expected path length as $\langle L\rangle>$ and the expected clustering coefficient as $\left\langle C_{\triangle}\right\rangle$. Newman et al. (2001) show that these quantities are given by:

$$
\begin{array}{r}
G_{0}(x)=f_{0}\left(\frac{g_{0}^{\prime}(x)}{g_{0}^{\prime}(1)}\right)=f_{0}\left(\frac{1}{\nu} g_{0}^{\prime}(x)\right) \\
z=G_{0}^{\prime}(1) \\
\langle L\rangle=1+\frac{\ln \left(N / G_{0}^{\prime}(1)\right)}{\ln \left(\left(\frac{f_{0}^{\prime \prime}(1)}{f_{0}^{\prime}(1)}\right)\left(\frac{g_{0}^{\prime \prime}(1)}{g_{0}^{\prime}(1)}\right)\right)} \\
\left\langle C_{\triangle}\right\rangle=\frac{M}{N} \frac{g_{0}^{\prime \prime \prime}(1)}{G_{0}^{\prime \prime}(1)}
\end{array}
$$


The corresponding expressions for the projection whose vertices are boards may be obtained similarly and are given by the following expression:

$$
\begin{aligned}
F_{0}(x) & =g_{0}\left(\frac{f_{0}^{\prime}(x)}{f_{0}^{\prime}(1)}\right) \\
z & =F_{0}^{\prime}(1) \\
\langle L\rangle & =1+\frac{\ln \left(M / F_{0}^{\prime}(1)\right)}{\ln \left(\left(\frac{g_{0}^{\prime \prime}(1)}{g_{0}^{\prime}(1)}\right)\left(\frac{f_{0}^{\prime \prime}(1)}{f_{0}^{\prime}(1)}\right)\right)} \\
\left\langle C_{\triangle}\right\rangle & =\frac{N}{M} \frac{f_{0}^{\prime \prime \prime}(1)}{F_{0}^{\prime \prime}(1)}
\end{aligned}
$$

Each quantity in Equation 3 and 4 (i.e. the mean degree, expected path length and clustering coefficient) can be calculated from the observed data. In the empirical work below we can calculate these separately for the ownership and control networks. For the control network we use equation 3 for the projection whose vertices are directors and 4 for the projection whose vertices are boards. Similarly, for the ownership network we can use equation 3 for the projection whose vertices are shareholders and 4 for the projection whose vertices are firms. Previous empirical work on smallworlds in the context of corporate governance has used the results of the NSW theory. For example, Conyon and Muldoon (2006) evaluate whether the board of directors in the UK can be considered a small-world.

\subsection{Random graphs II: Chung and Lu}

More recently, Fan Chung and Linyuan Lu have introduced a very convenient and attractive ensemble of random bipartite graphs that has a prescribed expected degree sequence (Chung and Lu, 2002a,b; Chung et al., 2003). That is, they start with the same ingredients as Newman et al. (2001, 2002), but use them in a different way. Their approach amounts to a sort of probabilistic hiring hall for corporate leadership: the probability that a given director serves on a given board depends only on the number of directorships she wants hold and the number of seats on the board. To the extent that their approach allows one to assemble randomly a corporate network similar to the real one, Chung and Lu's model is similar to that of Newman, Strogatz and Watts, but the Chung-Lu approach is slightly superior as it excludes certain unrealistic kinds of corporate network. For ex- 
Figure 2: Constructing a Chung-Lu random graph: the upper panel shows a small corporate world, while the lower panel illustrates that stage in construction of a CL-random network which determines the boards on which director $\mathrm{C}$ serves.

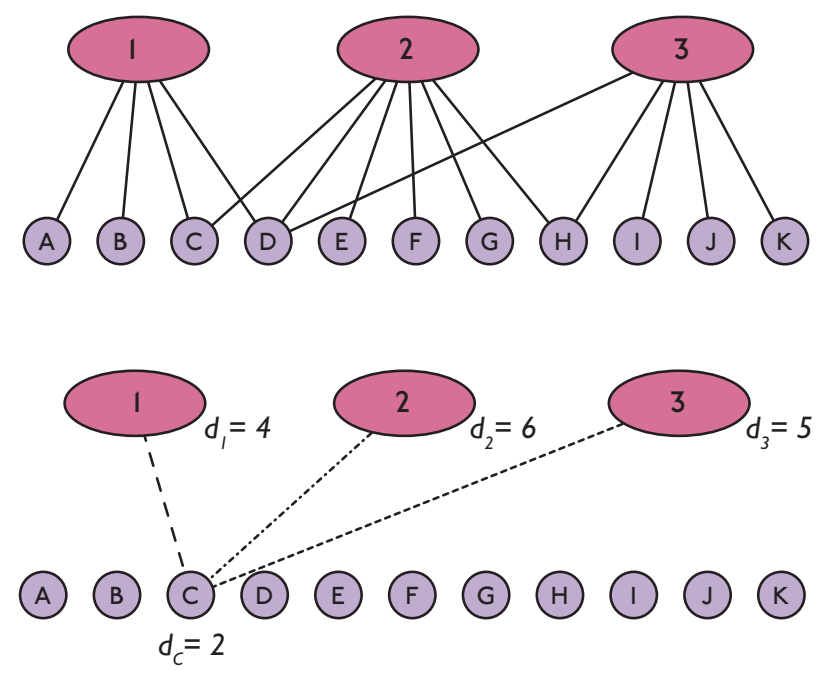

ample, almost every graph in the NSW family will include a few cases in which a single director holds multiple seats on the same board: the Chung-Lu family excludes such examples by design. Although such anomalous directors will appear only extremely rarely in a given NSW network (far too rarely to affect such summary statistics as $L$ and $C_{\triangle}$ for any realistically-sized corporate network), it is still appealing to work with a family of random graphs that includes no such cases.

To be concrete, we will illustrate the construction of a board network. Ownership networks can be similarly fashioned. Imagine that in the original data director $A$ served on $d_{A}$ boards (that is, she has degree $d_{A}$ in the affiliation network representing the real corporate world) and that board 1 consisted of $d_{1}$ directors. Then, in a Chung-Lu (CL) random graph, director $A$ would serve on board 1 with probability

$$
p_{A, 1}=d_{A} d_{1} / \rho
$$

where

$$
\rho=\sum_{\text {Boards } j} d_{j}=\sum_{\text {Directors } k} d_{k}
$$

is the total number of edges (or, equivalently, seat on boards) in the original network. This prescription ensures that, in expectation, each board has the same number of directors and each director holds the same number of directorships as in the real data. 
To see why, consider Figure 2. The upper panel shows a small corporate world with three boards and eleven directors: here the total number of edges $\rho$ is 15 . The lower panel illustrates those steps in the construction of a CL random network that determine which edges are incident on director $C$ : she serves on board 1 with probability

$$
p_{C, 1}=\frac{d_{C} d_{1}}{\rho}=\frac{2 \times 4}{15}=\frac{8}{15}
$$

Similarly, she serves on board 2 with $p_{C, 2}=12 / 15$ and on board 3 with $p_{C, 3}=10 / 15$. Thus her expected degree in the random network (the expected number of edges connected to vertex $C$ ) is

$$
\begin{aligned}
1 \times p_{1, C}+0 \times\left(1-p_{1, C}\right) & \\
+1 \times p_{2, C}+0 \times\left(1-p_{2, C}\right) & \\
+1 \times p_{3, C}+0 \times\left(1-p_{3, C}\right)= & 1 \times \frac{8}{15}+0 \times \frac{7}{15} \\
& +1 \times \frac{12}{15}+0 \times \frac{3}{15} \\
& +1 \times \frac{10}{15}+0 \times \frac{5}{15} \\
& =\frac{30}{15}+0 \\
& =2
\end{aligned}
$$

More generally, if director $C$ serves on $d_{C}$ boards in the real corporate world then her expected degree (number of directorships) in a CL-random network is

$$
\begin{aligned}
\sum_{\text {Boards } j} 1 \times p_{C, j}+0 \times\left(1-p_{C, j}\right) & =\sum_{\text {Boards } j} p_{C, j} \\
& =\sum_{\text {Boards } j} d_{C} d_{j} / \rho \\
& =d_{C}(1 / \rho) \sum_{\text {Boards } j} d_{j} \\
& =d_{C}
\end{aligned}
$$

where the final equality follows from Eqn. (6) above. Of course, the same argument works for any other director and a similar one for any board, so the simple prescription of Eqn. (5) allows us quickly to generate random graphs whose expected degree sequence matches that of the observed data. 


\subsection{Findings from previous research}

There has been a recent upsurge of interest in small-world models and their application to social networks (Newman, 2003; Jackson, 2005; Watts, 1999; Rowley and Baum, 2007). A comparatively small number of papers have applied small-world network analysis to the governance and control of organizations. For example, contemporary work on small-worlds and complex systems includes Dagnino et al. (2007), Walker (2007) and Cohen et al. (2007). None, to our knowledge, have simultaneously examined the ownership and control of firms, or used the types of techniques proposed in this paper (i.e. Chung-Lu graphs). However, it is important to briefly highlight some of the salient findings from the extant empirical literature.

In an important early paper Kogut and Walker (2001) examined the small-world ownership structure of German firms in the mid-1990s. Specifically, the 500 largest non-financial firms, and 50 financial firms. The authors conclude that the ownership structure of German firms can be characterized as a small-world when compared with an Erdős and Rényi (1959) Poisson random graph. In addition, their simulation results indicate the German small-world is robust to disruption. The properties of the small-world remain intact even when ownership ties are removed.

In practice, however, the Poisson random graph is not a good description of social networks. Newman et al. (2001) generalize the random graph model in a number of ways to better understand the formation of social networks. For example, they consider non-Poisson degree distributions and the representation of affiliation networks as bipartite graphs. As noted in Section 3 they derive exact expressions for the degree distribution, the average path-length, and clustering coefficient within a graph (among other results). They apply the theory to some real-world graphs including Fortune 1000 company directors. Their analysis shows remarkable agreement between actual data and the random graph model for some statistics (the clustering coefficient and the average number of directors on a board) but not others (the number of board interlocks). ${ }^{13}$

Davis et al. (2003) also examined the network structure of US corporate boards during the 1980s and 1990s. They examine the small-world properties of directors and companies in each of the years 1982, 1990, and 1999. They find the presence of a small-world among the corporate elite (short path-lengths and high clustering) when compared with a Poisson random graph. They conclude that the aggregate connectivity of the social network of boards seems remarkably stable. Such

\footnotetext{
${ }^{13}$ Uzzi and Spiro (2005) examined the small-world among collaboration and creativity of artists who produced Broadway musicals from 1945 to 1989 using Newman et al. (2001) methods.
} 
connectivity is an intrinsic property of the network. Baum et al. (2003) examined the small-world of Canadian capital markets, specifically investigating investment bank syndicates. Two banks are connected if they participated in an underwriting syndicate together. They document the presence and evolution of a small-world between 1956 and 1989. The Poisson distribution is used as the benchmark to compare calculated network measures.

Conyon and Muldoon (2006) used techniques developed by Newman et al. (2001) to investigate the small-world of corporate boards in the United States, Germany and the United Kingdom. They demonstrated two important findings. First, the network of boards and directors is, in fact, no smaller than would excepted by chance from a randomly assembled corporate universe. That is not to say that this is the 'true' mechanism by which the corporate world is constructed (that is absurd) only that the type of random graph models described by Newman et al. (2001) are remarkably good at predicting the average clustering and path lengths in the network. Second, Conyon and Muldoon (2006) find, in agreement with the smaller study of Newman et al. (2001), that there is positive degree correlation in each of the economies studies. That is a tendency for directors who hold many directorships to sit on boards with other directors who too hold many directorships. They argue that this is consistent with 'social homophily effects' described in the psychology literature (McPherson et al., 2001).

Our paper tests the predictions arising from the small-world model and contrasts it to the random-graph alterative hypothesis. It is also important to mention a class of research that investigates the formation and evolution of social networks by actors involved in a rational cost-benefit calculus. Jackson and Wolinsky (1996) formulate a model where actors incur some costs of maintaining social ties but also benefits from their location within the resulting dense network of ties. The cost and benefit functions of the rational link-making actors are parameterized and the subsequent equilibrium structures analyzed. See also the related work of Dutta and Mutuswami (1997), Kim and Wong (2007) and Jackson and Watts (2002). This thematic research is also expanded in Doreian (2006) who provides an analytical model of the transitions between networks on the lattices of all graphs with a fixed number of vertices through the addition and deletion of ties. See also Doreian (2007). Other theoretical research too has examined the formation of networks (see Jackson (2005)). Cowan and Jonard (2007) analyze the formation of innovation (alliance)networks using graph theory. In their model, creating an alliance increases the chances of innovation if the knowledge set of potential partners is complimentary. Since innovation changes the firms knowl- 
edge portfolio so the network evolution changes. They show the structural properties of networks (degree and clustering) arising from alliance partner choice which is driven by complementarities in firm's knowledge portfolios.

In other analytical work related to the themes of our paper Jackson and Rogers (2005) develop a model where small-worlds arise from the costs and benefits of network formation. In their model the costs of maintaining a relationship between two actors (e.g. boards) depends on their proximity to each other. It is relatively easy for near acquaintances to maintain friendships and form strong bonds. These low costs help explain why one observes high local clustering in the network. It also explains the presence of short average path lengths. Consider a hypothetical situation where the network has many densely clustered groups, but the average path length is high because of the absence of links between the groups. Again, we might think that forming such a link across groups is, at first sight, costly. However, the absence of links across groups means that making one such link can provide substantial benefits because it opens up access to many other agents. Forming a single link can connect one agent to many other agents by reducing the distance between them and this is exactly what makes that link valuable. This type of research shows that understanding the underling economic incentives leading to network formation is critical field of research to complement empirical analyses.

\section{Empirical Results}

\subsection{Data}

To examine the social network of ownership and control in Britain we used data supplied by Hemscott (http://www.hemscott.com) ${ }^{14}$. Hemscott data has been used in previous corporate governance research (e.g. Conyon and Muldoon, 2006). We treat the ownership and board networks as separate bipartite graphs. In the bipartite graph of firms and owners, the firm represents one set of vertices and the shareholders the other. In the bipartite graph of firm control, the board represents one set of vertices and the directors (i.e. the board members) the other - as illustrated in Figure 1. The board data are snap-shot of all publicly traded firms listed on the London Stock Exchange in 2000. It consists of all executive and non-executive directors at UK public firms (other senior

\footnotetext{
${ }^{14}$ Hemscott - Hemmington Scott — is a leading international provider of quality business data, including information about corporate governance, and investor relations services
} 
Table 3: Descriptive statistics - UK

\begin{tabular}{lccccccc}
\hline & $\mathbf{N}$ & mean & $\mathbf{p 5 0}$ & $\mathbf{p 2 5}$ & $\mathbf{p 7 5}$ & $\mathbf{m i n}$ & $\mathbf{m a x}$ \\
\hline The Board & & & & & & & \\
Board size & 2055 & 6.65 & 6.00 & 5.00 & 8.00 & 2.00 & 22.00 \\
Boards per director & 10,920 & 1.25 & 1.00 & 1.00 & 1.00 & 1.00 & 13.00 \\
& & & & & & & \\
Ownership & & & & & & & \\
Shareholder per firm & 1,932 & 4.78 & 4.00 & 3.00 & 6.00 & 1.00 & 22.00 \\
Firms per shareholder & 3,739 & 2.47 & 1.00 & 1.00 & 1.00 & 1.00 & 184.00 \\
\hline Data Source: Hemscott, 2000 & & & & & & &
\end{tabular}

officers are excluded). Likewise, the ownership data consists of firms and their owners, where there is at least an ownership stake exceeding 3\%. We consider only non-board owners in year 2000 .

Some basic network statistics on the structure of ownership and control are contained in Table 3. The data set contains 2,055 separate firms and 10,920 unique board members (directors). In total there are 13,671 director seats-some directors are members of more than one board. The average board contains approximately seven members and the average British director is a member of 1.25 boards (including membership of his or her primary board). ${ }^{15}$ Only a minority of UK board members hold more than one directorship. Indeed, the director at the 75th percentile still has only one board position. The maximum number of directorships held by one person is 13 .

In the data set we can separately identify a firm and its set of non-board shareholders. The descriptive statistics are contained in Table 3. We were able to analyze 1,932 unique firms. These firms have 3,739 separate shareholders. A typical firm has, on average, about five different shareholders. Conversely, each shareholder owns shares in about 2.5 separate firms. The figure conceals a very strong skew in the data. There are some shareholders who own shares in many companies. For example, the shareholder at the 99th percentile holds shares in thirty-one separate firms. One shareholder (the maximum) owns at least a $3 \%$ share stake in 184 firms.

\subsection{The small-world of ownership and control}

Table 4 presents empirical evidence on the small-world of ownership and control among UK firms using the methodology of Newman et al. (2001). The hypothesis under investigation: can the real-

\footnotetext{
${ }^{15}$ Prior UK research suggests boards are a bit larger than this, but our data includes even the smallest of boards-a population typically excluded from previous studies. In our data board size is an increasing function of firm size measured by market capitalization.
} 
world data be adequately represented by a random-graph with a prescribed degree distribution. The lower-half of the table contains information on the 'ownership' network: the unipartite firm and owner projections. The upper-half of the table contains information on the 'control' network: the unipartite board and director projections. In each case we report the number of vertices $(N)$, the number of vertices in the largest connected component $(L C C)$, the degree $(D)$, the average path length $(L)$, and the clustering coefficient $\left(C_{\triangle}\right)$. The brackets $(<>)$ are an expectations operator of the large-graph limits described by Newman et al. (2001).

The data show that the largest connected component is a sizable fraction of the available vertices in the network (between about $76 \%$ and $85 \%$ ). Even though most directors only have one board position, the few that have more than one prove to be more than sufficient to link the majority of corporations together. Similarly, the typical shareholder owns stock in a comparatively small number of firms. However, the few that own shares in more than one firm are enough to link together the majority of firms in the data set. In itself, the presence of such a "giant component" 16 in the ownership and control network, is a remarkable finding.

The 'degree' of a vertex provides one indication of the importance of that actor in the network. Consider the board network. Table 4 shows that the typical board is connected to about six otherswhere connections arise from a shared director. The expected value of the statistic is about six too. At face value it seems that the real data is in accord with the random-graph model. The board's degree is no greater or less than would be expected by chance (but see below). Similarly, the typical director is connected to about nine others, which, of course, includes members of his or her own board. Again, there is strong agreement between the actual data and theoretical prediction. Consider next the ownership network. Table 4 shows that the typical firm is connected to about one hundred and twenty others (!), where here connectivity arises from a shared owner. Even so, the actual degree is slightly less than what would be expected by chance given the observed degree sequences.

Can the network of ownership and control in the UK be characterized as a small-world? Section 3 illustrated that small-worlds are characterized by relatively short path lengths and high clustering. Consider the path lengths for each of the four projections in Table 4. We observe much agreement between the actual data and the expected values arising from the NSW method. If anything, the

\footnotetext{
${ }^{16}$ The term originated in the work of Erdős and Rényi, who proved that if the expected degree $z$ exceeds 1.0 in a Poisson random graph then, with high probability, the largest connected component contains the majority of vertices.
} 
Table 4: The small-world of UK ownership and control

\begin{tabular}{lcccccccc}
\hline & $N$ & $L C C$ & $D$ & $\langle D\rangle$ & $L$ & $\langle L\rangle$ & $C_{\triangle}$ & $\left\langle C_{\triangle}\right\rangle$ \\
The Board & & & & & & & & \\
Board projection & 2,055 & 1,592 & 5.686 & 6.106 & 5.455 & 4.078 & 0.376 & 0.327 \\
Director projection & 10,920 & 8,323 & 9.013 & 9.090 & 6.275 & 4.772 & 0.597 & 0.544 \\
& & & & & & & & \\
Ownership & & & & & & & & \\
Firm projection & 1,932 & 1,650 & 120.83 & 136.181 & 2.302 & 1.499 & 0.519 & 0.392 \\
Owner projection & 3,739 & 3,029 & 12.703 & 15.717 & 3.226 & 2.053 & 0.164 & 0.041 \\
\hline
\end{tabular}

Data Source: Hemscott, 2000

actual values are slightly greater than the expected. It would, therefore, be tempting to conclude that path-lengths are really no different from what we would expect from a random graph with a known degree distribution. The NSW method prompts us to the conclude that the world of ownership and control is not 'small'. There are two important observations to make. First, we would stress that the short-path length outcome is still quite a remarkable finding. The mean geodesic in any of the projections is a very small fraction of the number of vertices in the largest connected component. For instance, the mean geodesic (i.e., shortest distance) for the board projection is about 5.5 whereas the number of vertices is 1,592 - or about $0.4 \%$ of the vertices in the largest connected component. Indeed, for the owner projection, the observed geodesic is 3.2 and the number of vertices in the connected component is 3,029 (or about $0.1 \%$ ). Such short path lengths can act as important and powerful routes for the spread of business practices, knowledge and ideas or even rumors (Cowan and Jonard, 2004). ${ }^{17}$ Second, the procedure advocated by Newman et al. (2001) only permits us to compare the real-world data to the expected value of the large-graph limit. We do not have any confidence bounds, for example, to compare to our calculated statistic. The Chung and Lu $(2002 a, b)$ method, on the other hand, permits us to simulate many random corporate worlds with a prescribed degree sequence. The outcome of the simulations gives us a range of values on the small-world statistics which we can compare the actual values to.

The NSW clustering coefficient results contained in Table 4 show broad agreement between actual and expected values for the board of director graphs, but not the ownership networks. For the board projection $C_{\triangle}$ takes a value of 0.376 which is similar to the expected value $(=0.327)$. The director projection reveals a qualitatively similar result. The NSW analysis leads us to conclude

\footnotetext{
${ }^{17}$ For a Poisson random graph the mean geodesic can be expressed as $l=\log (N) / \log (z)$. In the case of the board projection this is approximately $l=\log (1,592) / \log (6.65)=3.324$. The Poisson random graph, like the random graph with a constrained degree distribution, predicts a short mean geodesic relative to the number of vertices.
} 
that boards are not particularly cliquish. In contrast, the clustering coefficient in the ownership network is greater than expected suggesting that ownership ties are more 'clubby' than expected by chance. For instance, in the firm projection of the ownership network $C_{\triangle}$ takes a value of 0.519 which is greater than expected $(=0.392)$. A more pronounced conclusion is observed for the ownership projection.

\subsection{Chung-Lu simulation results}

The results so far pertain to actual small-world statistics compared to their expected values using the machinery introduced by Newman et al. (2001). As noted their predictions are large-graph limits for a certain ensemble of randomly-assembled social networks. Unfortunately, the procedure does not permit us to say anything about the confidence intervals within which actual small-world values lie. To determine whether the world of UK ownership and control really is 'small' we simulated a set of corporate universes with a prescribed expected degree sequence. We followed the methods introduced by Chung and Lu (2002a,b); Chung et al. (2003). Again, the main hypothesis under investigation is whether the actual data can be adequately represented by a random-graph with a prescribed degree distribution. The results of the simulations are plotted in Figures 3 and 4.

Consider Figure 3 which relates to the board of directors (corporate control). The upper row contains information from the board projection, whereas the lower row pertains to the director projection. Three network statistics are presented: the average degree $(D)$, the path length $(L)$ and the clustering coefficient $\left(C_{\triangle}\right)$. In addition, the frequency distribution arising from the CL random graph simulations are given. We also report the actual and NSW expected values of each statistic. Consider the board projection. The calculated values of the degree, path length and clustering measures each lie outside the range predicted by the Chung-Lu simulations. A Mann-Whitney test confirmed this. For example, $H 0: \operatorname{pr}(\mathrm{CL}$ clustering = actual clustering) yielded $z=-1.729$ with Prob $>|z|=0.0839$. The results are qualitatively similar for the director projection. Once again the calculated actual degree, path-length and clustering measures lie outside the range predicted by the Chung-Lu random graph model. In both projections we find that the actual path lengths are longer than expected by chance. However, we find that clustering is significantly greater than predicted by the Chung-Lu random-graph model. We deduce that the world of the corporate elite is 'small' in the sense that it is more 'clubby' or 'cliquish' than would be expected by chance. These 
Figure 3: UK Corporate Boards: The small-world of the UK corporate elite. Chung-Lu random graphs: 500 simulations.

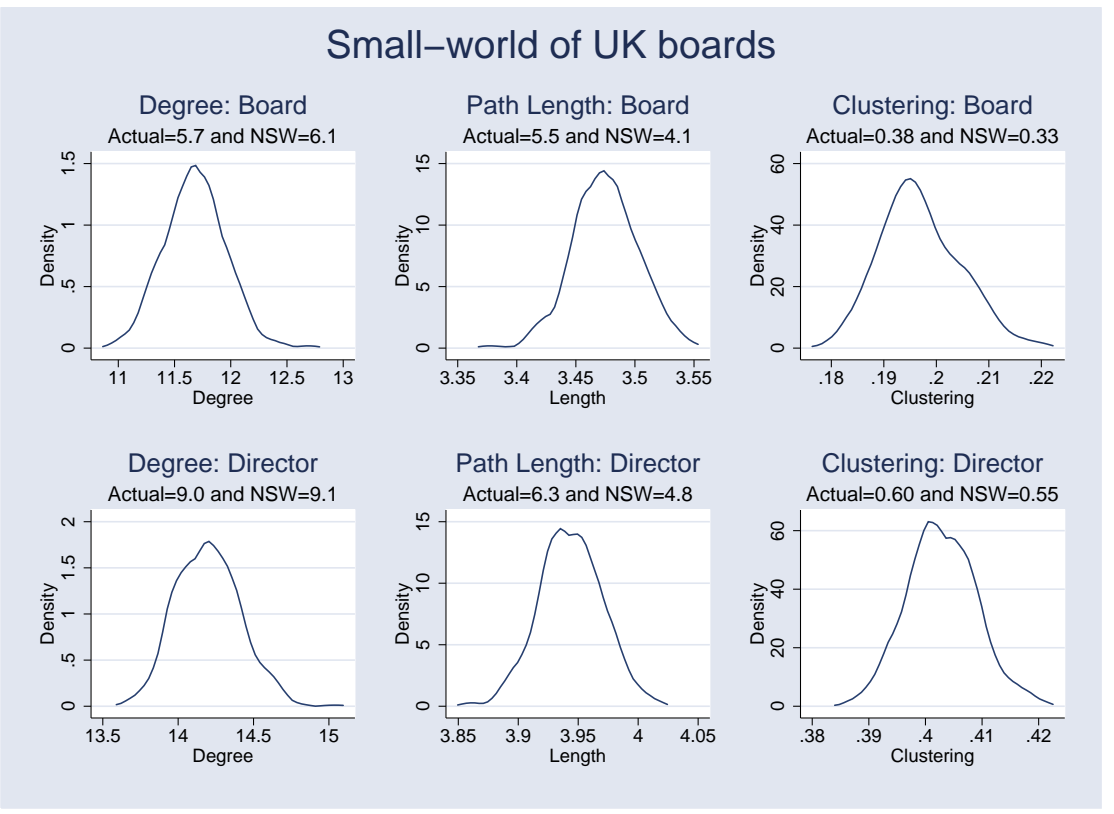

empirical results suggest the presence of additional social structure in the network of board control that is not accounted for by the random-graph model.

Figure 4 relates to the small-world of UK company ownership. The upper-row contains information from the firm projection, whereas the lower-row pertains to the owner projection. The format of Figure 4 is the same as in Figure 3. In the firm projection the average degree is not significantly different from that expected in a Chung-Lu random graph with prescribed degree sequence. [Mann-Whitney $H 0: \operatorname{pr}(\mathrm{CL}$ degree $=$ actual degree $) z=1.169$ with $\operatorname{Prob}>|z|=0.2426$ ]. This is not the case in the owner projection, where the actual degree is less that predicted by the Chung-Lu simulations. The small-world statistics are both very different from that predicted by the random-graph model. In both the firm and owner projections the path-lengths $(L)$ are significantly longer than that predicted by the Chung-Lu random graph model. In this sense the world is not 'small': path-lengths are not shorter than expected by chance. On the other hand the clustering coefficient $\left(C_{\triangle}\right)$ is significantly greater than expected by the random-graph model. Once again, we deduce that the world of corporate ownership is 'small' but only in the sense that it is more 'clubby' or 'cliquish' than would be expected by chance. Firms are connected to other firms by means of a 
Figure 4: UK Ownership: The small-world of the corporate ownership. Chung-Lu random graphs: 500 simulations.

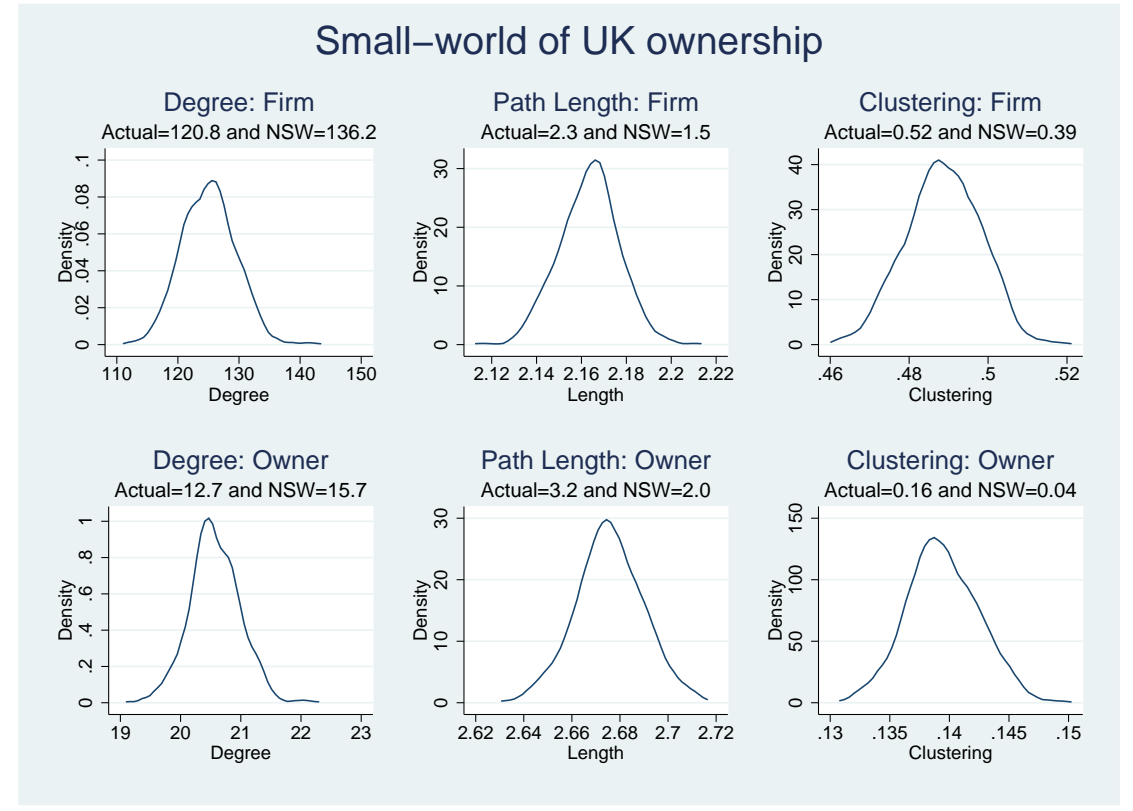

common shareholder more frequently than one would expect by chance. Again, the data suggests the presence of additional social structure in the ownership network that is not accounted for by the random-graph model.

\subsection{Financial institutions and the small-world}

Previous research has argued persuasively that financial institutions such as banks are crucial to understanding the topology of the corporate board network. Sociological research, inspired by Brandeis (1914) and Mills (1956), has argued that bankers may be appointed to boards as a way for financial institutions to exercise power and influence over non-financial institutions. An alternative perspective is that both financial and non-financial institutions receive cross-fertilization benefits by adding directors of each type to their respective boards. For example, see the analysis of the formation of the inner circle by Useem (1984). Davis et al. (2003) concluded: 'we can derive two main conjectures regarding the underpinnings of the elite network. On the one hand, several authors point to the central importance of banks in ordering, or even creating, the network. In this view, the fact that the corporate elite is well-connected results from the presence of particular 
Table 5: The small-world of corporate boards: including and excluding financial institutions

\begin{tabular}{lcccccccc}
\hline & $N$ & $L C C$ & $D$ & $\langle D\rangle$ & $L$ & $\langle L\rangle$ & $C_{\triangle}$ & $\left\langle C_{\triangle}\right\rangle$ \\
All firms & & & & & & & & \\
Board projection & 2,055 & 1,592 & 5.686 & 6.106 & 5.455 & 4.078 & 0.376 & 0.327 \\
Director projection & 10,920 & 8,323 & 9.013 & 9.090 & 6.275 & 4.772 & 0.597 & 0.544 \\
& & & & & & & & \\
Non-financials & & & & & & & & \\
Board projection & 1,398 & 761 & 3.806 & 3.961 & 6.565 & 4.863 & 0.341 & 0.278 \\
Director projection & 8,503 & 4,846 & 9.201 & 9.237 & 7.166 & 5.601 & 0.679 & 0.665 \\
\hline
\end{tabular}

Data Source: Hemscott, 2000

institutions at the core, acting as a switchboard connecting disparate directors. In contrast, others emphasize the unplanned nature of the network: members of the corporate elite all seem to know one another simply as an unintended consequence of increasing economic concentration.' Davis et al. (2003) present empirical evidence from the US showing that during the 1960s and 1980s the most highly connected organizations were indeed banks. However, they also note that bank centrality seems to have eroded at the turn of the century.

To test the importance of financial institutions in the corporate network we conducted a very simple experiment. First, we took the list of firms and directors in the board network described in sub-section 4.1 (call these 'All firms'). We then excluded banks, financial institutions and investment trusts from our initial list of firms yielding a new network (call this new graph 'Nonfinancial institutions'). We then re-calculated the graph statistics presented in Section 4. If financial institutions are like non-financial institutions then their removal would have little effect on the network measures. Conversely, if financial institutions are 'at the core, acting as a switchboard connecting disparate directors' then we might expect to observe salient differences between the original 'All firms' board graph and the one without financial institutions. ${ }^{18}$

In Table 5 we present empirical evidence based on a comparison of calculated network statistics to Newman et al. (2001) expected values. The upper-half replicates the board network results in Table 4. The lower-half contains evidence based on the graph which excludes financial institutions. Disrupting the original network, by removing financial institutions, has a number of consequences. In the board-projection the mean degree is smaller, the average path-length is longer and the

\footnotetext{
${ }^{18}$ The analysis compares 'Non-Financial' firms to the larger set of 'All Firms'. One might instead compare the Non-Financial network to one (or a group) derived from the full 'All Firms' network but deleting randomly-selected firms to make the new set of 'All Firms' network contain the same number of firms as the 'Non-Financial' network. We leave this possibility for future research.
} 
Figure 5: The UK Board Network: Chung-Lu random graphs: 500 simulations. Analysis on all firms and non-financial institutions. In the figures 'NF' refers to 'Non-financial institutions'.

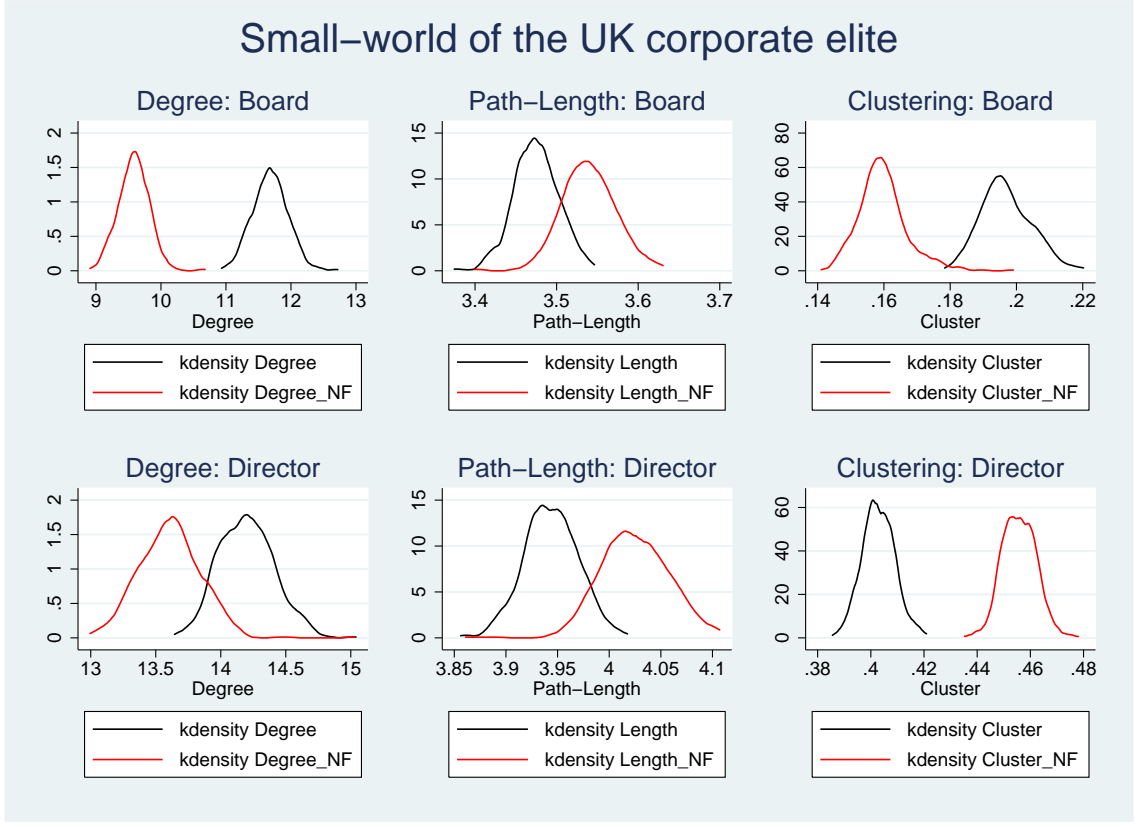

mean clustering-coefficient is smaller. In the director projection we find the mean degree is slightly greater, the average path-length is longer and the mean clustering-coefficient is greater.

We next simulated a set of corporate universes with a prescribed expected degree sequence using Chung and Lu (2002a,b); Chung et al. (2003) methods. We did so for the network of all firms and then separately for the network of non-financial institutions (namely, those firms in the original graph excluding banks, investment trusts, etc.). The principal hypothesis under investigation is that the network statistics arising from the simulations are the same for both graphs. If banks and financial institutions are key to the network we would expect to reject this hypothesis. The results of the simulations are plotted in Figure 5. The maintained hypothesis is rejected: network topology is influenced by the presence (or absence) of financial institutions. Consider the board projection. The network of non-financial firms has a smaller mean degree, longer average path-length and smaller mean clustering-coefficient. In the director projection, the non-financial network of firms has a lower mean degree, longer average path-length, and greater mean clustering-coefficient. The differences in the simulated network-statistics between the 'All Firm' graph and the 'Non-Financial Firms' network are all significant based on a Mann-Whitney U test. For example in the board 
projection, $H 0: \operatorname{pr}$ (Clustering in all firms = clustering in non-financial firms) yielded $z=27.274$ with $\operatorname{Prob}>|z|=0.000$. We conclude that financial institutions are important and give rise to different network topologies. Specifically, in the board graph, the exclusion of finance institutions leads to lower network connectivity (smaller degree), longer path lengths and networks that are less 'clubby' (lower clustering coefficient). Our research complements recent research by Neuman et al. (2007) who analyze the relations among bank mergers, changes in boards and their networks. They find that 'while the largest banks have become even larger through mergers, their boards have stayed roughly the same size with the same pattern of connections, leaving banks relatively less central in the intercorporate network. And while global banks previously had more globallyoriented boards, this is no longer the case, as the link between board networks and strategy has become more tenuous.'

\section{Conclusions}

In this paper we have presented a social network analysis of the ownership and control of AngloSaxon firms. Our paper contributes to an emergent literature which is trying to understand social networks by appealing to a class of small-world models (Newman, 2003; Jackson, 2005). Our paper makes the following contributions to extant corporate governance research. First, we argue that a network approach to understanding the ownership and control of firms is relevant and germane. It complements the canonical agency model, which typically ignores connections between firms. Such links promote the rapid diffusion of knowledge and ideas through the corporate network (Cowan and Jonard, 2004).

Second, our research paper addressed the question: can the social network structure of ownership and control be characterized as a 'small-world'? As we noted, a small-world occurs when 'path-lengths' are relatively short and 'clustering' is relatively high. However, to answer this question satisfactorily one needs to address the associated question: how 'small' do we expect that world to be? Simply calculating actual small-world measures alone does not tell us much as we still need to decide on an appropriate benchmark. An innovation contained in this paper is to compare the actual social network of ownership and control with an ensemble of random-graphs introduced by Chung and Lu (2002a,b); Chung et al. (2003). As such, our paper continues a stream of research that is informed by developments in graph theory and the structure of complex networks - especially 
the important contributions by Newman (2003) and Newman et al. (2001, 2002).

To investigate the ownership and control network of Anglo-Saxon firms we used year 2000 data on British firms. Our analysis revealed a number of empirical findings. We confirmed the well-known fact that ownership of UK publicly traded firms is diffuse. Firms are owned by many shareholders, each of whom owns a relatively small share-stake. Our principal findings are: first, in general the Chung-Lu random-graph model is not particularly well-suited to describing the ownership and control of British firms. Our simulations suggest measurable and significant differences between the actual data and theoretical predictions. This strongly suggests the presence of additional social structure in the network of ownership and control that is not accounted for by the random graph model. Only in some cases did we find that the random-graph model seemed to predict with great accuracy the behavior of the real world.

Second, we find important evidence suggesting that the world of UK ownership and control is, indeed, 'small'. It is small in the sense that the measured path-lengths in both the ownership and board projections are small compared with the number of available vertices in the largest connected component. However, the statistical evidence suggests that these path-lengths are actually not smaller than would be expected in a randomly-assembled corporate universe with the prescribed degree sequence. On the other hand we do find that the ownership and control network is decidedly more 'clubby' or 'cliquish' than would be expected by chance. Generally, we found that the clustering measures in both the ownership and board graphs were greater than predicted by the Chung and Lu (2002a,b); Chung et al. (2003) random-graph model. Boards tend to be connected to other boards by a shared director more frequently than one would observe by chance. In addition, firms are connected to other firms by means of a common shareholder more frequently than one would expect by chance. There is important social structure in the network that is yet to be accounted for. It is in this context that analytical research is important. If the corporate world is not easily represented as a random-graph, then future research needs to focus on alternative explanations of the observed network structure. A potentially fruitful avenue is the class of theoretical small-world models recently analyzed by Jackson (2005) and Jackson and Rogers (2005) and other analytical research such as Jackson and Wolinsky (1996), Dutta and Mutuswami (1997), Kim and Wong (2007) and Jackson and Watts (2002).

Finally, we extended our empirical analysis to examine the properties of the board network when financial institutions are excluded. Previous research has argued that banks are important 
conduits creating connectivity in corporate networks. In our experiment we concluded that financial institutions are indeed important and give rise to different network topologies. Specifically, we found in the board graph that the exclusion of finance institutions leads to lower network connectivity (a smaller degree was observed), longer path lengths and networks that are less 'clubby' (there was a lower clustering coefficient). Our results suggest the need for further research to examine the sensitivity of network statistics to the inclusion or exclusion of different types of actors in the network.

Overall, our paper has contributed to the governance literature by presenting a small-world analysis of the ownership and control of British publicly traded firms. We have done so by using relevant techniques from computational graph theory (i.e. Chung-Lu graphs). We hope that the research and results contained in this paper provide a stimulus to future graph theoretic analyses of corporate governance phenomena. 


\section{References}

Baum, Joel A. C., Andrew V. Shiplov and Tim J. Rowley (2003), 'Where do small worlds come from?', Industrial and Corporate Change 12, 697-725.

Berle, Adolf and Gardiner Means (1932), The Modern Corporation and Private Property, Commerce Clearing House, Chicago, U.S.A.

Bollobás, Bélla (2001), Random Graphs, second edn, Cambridge University Press, Cambridge.

Brandeis, Louis D. (1914), Other Peoples Money: And How the Bankers Use It, New York: Frederick A. Stokes., New York, U.S.A.

Burt, Ronald (1992), Structural Holes: The Social Structure of Competition, Harvard University Press, Cambridge.

Chung, Fan and Linyuan Lu (2002a), 'The average distance in random graphs with given expected degrees', Proceedings of National Academy of Sciences U.S.A. 99(25), 15879-15882.

Chung, Fan and Linyuan Lu (2002b), 'Connected compnents in a random graph with given degree sequences', Annals of Combinatorics 6, 125-145.

Chung, Fan, Linyuan Lu and Van Vu (2003), 'The spectra of random graphs with given expected degrees', Proceedings of National Academy of Sciences U.S.A. 100(11), 6313-6318.

Cohen, Lauren, Andrea Frazzini and Christopher J. Malloy (2007), 'The Small World of Investing: Board Connections and Mutual Fund Returns', SSRN eLibrary .

Conyon, Martin J. and Mark R. Muldoon (2006), 'The small world of corporate boards', Journal of Business Finance and Accounting 33, 1321-1343.

Cowan, Robin and Nicolas Jonard (2004), 'Network structure and the diffusion of knowledge', Journal of Economic Dynamics and Control 28, 1557-1575.

Cowan, Robin and Nicolas Jonard (2007), 'Knowledge portfolios and the organization of innovation networks', Working paper. Presentation at the Rotman Conference on Network Strategy, May 2007 .

Dagnino, Giovanni, Gabriella Levanti and Arabella Li Destri (2007), 'Evolutionary dynamics of interfirm networks: A complex systems perspective', Working paper. Presentation at the Rotman Conference on Network Strategy, May 2007.

Davis, Gerald F., Mina Yoo and Wayne E. Baker (2003), 'The small world of the corporate elite, 1982-2001', Strategic Organization pp. 301-326.

Doreian, Patrick (2006), 'Actor network utilities and network evolution', Social Networks, 28(2), 137-164.

Doreian, Patrick (2007), 'Network location, actor utilities and network evolution', Working paper. Presentation at the Rotman Conference on Network Strategy, May 2007. 
Dutta, Bhaskar and Suresh Mutuswami (1997), 'Stable networks,', Journal of Economic Theory, 76(2), 322-344.

Erdős, Paul and Alfréd Rényi (1959), 'On random graphs', Publ. Math. Debrecen 6, 290-297.

Erdős, Paul and Alfréd Rényi (1960), 'On the evolution of random graphs', Publ. Math. Inst. Hung. Acad. Sci., Ser. A 5, 17-61.

Franks, Julian R., Colin Mayer and Stefano Rossi (2005), Ownership: Evolution and regulation, ECGI working paper 2005.15, European Corporate Governance Institute. Available at SSRN: http://ssrn.com/abstract $=354381$.

Jackson, Matthew (2005), The economics of social networks, in R.Blundell, W.Newey and T.Persson, eds, 'Proceedings of the 9th World Congress of the Econometric Society', Oxford University Press. forthcoming.

Jackson, Matthew and B. Rogers (2005), 'The economics of small worlds', Journal of the European Economic Association 3, 617-627.

Jackson, Matthew O. and Alison Watts (2002), 'The evolution of social and economic networks', Journal of Economic Theory, 106(2), 265-295.

Jackson, Matthew O. and Asher Wolinsky (1996), 'A strategic model of social and economic networks', Journal of Economic Theory, 71(1), 44-74.

Kim, Chongmin and Kam-Chau Wong (2007), 'Network formation and stable equilibrium', Journal of Economic Theory, 133(1), 536-549.

Kogut, Bruce and Gordon Walker (2001), 'The small world of Germany and the durability of national networks', American Sociological Review 66, 317-335.

McPherson, Miller, Lynn Smith-Lovin and James Cook (2001), 'Birds of a feather: Homophily in social networks', Annual Review of Sociology 27, 415-444.

Milgram, Stanley (1967), 'The small-world problem', Psychology Today 2, 60-67.

Mills, Charles Wright (1956), The Power Elite, New York, New York,Oxford.

Neuman, Eric, Jerry Davis and Mark Mizruchi (2007), 'Networks and industry consolidation in u.s. global banking, 1986-2004', Working paper. Presentation at the Rotman Conference on Network Strategy, May 2007 .

Newman, Mark E. J. (2003), 'The structure and function of complex networks', SIAM Review 45, 167-256.

Newman, Mark E.J., Duncan J. Watts and Steven H. Strogatz (2002), 'Random graph models for social networks', Proc. Nat. Acad. Sci. U.S.A. 99, 2566-2572.

Newman, Mark E.J., Steven H. Strogatz and Duncan J. Watts (2001), 'Random graphs with arbitrary degree distributions and their applications', Physical Review E 64. 
Rowley, Tim and Joel Baum (2007), 'The dynamics of network strategies and positions', Working paper. Presentation at the Rotman Conference on Network Strategy, May 2007.

Tirole, Jean (2005), The Theory of Corporate Finance, Princeton University Press, Princeton and Oxford.

Useem, Michael (1984), The Inner Circle, Oxford University Press, New York,Oxford.

Uzzi, Brian and Jarrett Spiro (2005), 'Collaboration and creativity: The small world problem', American Journal of Sociology 111(2), 447-504.

Walker, Gordon (2007), 'The rise of ecommerce as an epidemic in the small world of venture capital', Working paper. Presentation at the Rotman Conference on Network Strategy, May 2007.

Wasserman, S. and K. Faust (1994), Social Network Analysis: Methods and Applications, Cambridge University Press, Cambridge.

Watts, Duncan J. (1999), 'Networks, dynamics, and the small-world phenomenon', American Journal of Sociology 105, 493-527.

Wilf, Herbert S. (1990), Generating functionology, Academic Press Professional, Inc., Academic Press Professional, Inc. San Diego, CA, USA. 